18.2 primary care contacts per patient year compared with 8.7 for non-HE controls $(\mathrm{p}<0.001)$.

Conclusion HE was associated with increased risk of liverrelated hospital admissions and increased GP attendances.

Disclosure of Interest J. Orr: None Declared, C. Morgan Consultant for: Norgine;, M. Hudson: None Declared, S. JenkinsJones Consultant for: Norgine, P. Conway Employee of: Norgine, A. Radwan Employee of: Norgine, C. Currie Consultant for: Norgine.

\section{PTU-128 A WEB-BASED SURVEY TO INVESTIGATE PHYSICIANS AND INTENSIVISTS' ATTITUDES TO CRITICAL CARE ADMISSION FOR CIRRHOSIS AND MULTIPLE ORGAN DYSFUNCTION}

${ }^{1} \mathrm{P}$ Berry*, ${ }^{2} \mathrm{SJ}$ Thomson, ${ }^{3} \mathrm{M}$ Peck, ${ }^{4} \mathrm{~T}$ Standley. ${ }^{1}$ Gastroenterology and Hepatology, Frimley Park Hospital, Camberley; ${ }^{2}$ Gastroenterology and Hepatology, Western Sussex Hospitals, Worthing; ${ }^{3}$ Anaesthetics and Intensive Care, Frimley Park Hospital, Camberley; ${ }^{4}$ Anaesthetics and Intensive Care, Western Sussex Hospitals, Worthing, UK

\subsection{6/gutjnl-2014-307263.202}

Introduction Hospital admissions for cirrhosis and related complications are rising and patients are getting younger. Hence, physicians are increasingly faced with making difficult referrals to intensive care for patients with multiple organ dysfunction. We examined the attitudes of a mixed cohort of physicians and intensivists, including trainees, to compare critical care admission decisions for a range of medical diagnoses including cirrhosis.

Methods A web survey containing eight clinical scenarios, including one describing a 45 year old man with severely decompensated ALD (bilirubin $410 \mathrm{umol} / \mathrm{L}$ ), sepsis and renal failure (prior to resuscitation) was advertised via email to trusts in the south of England. Respondents were asked to rate the degree with which they would advocate for ICU admission on a scale on 1-10 ( 1 = would not consider ICU, $10=$ insist on ICU). All cases had similar SOFA scores (10-11). Other cases included pneumonia, chronic airways disease, GI bleeding with loss of output, relapsed myeloma, post operative aspiration, ruptured $\mathrm{AAA}$, and CKD requiring renal replacement. Opinions on the level of organ support to be offered, or alternatively the ceilings of de-escalated care were further explored.

Results Of 144 respondents, 23\% were consultant physicians, $22 \%$ consultant anaesthetists and 22\% specialist trainees. Mean advocacy score for ALD was 7.2, which ranked 4 out of 8 scenarios. COPD scored lowest, with a mean score of 4.9 , acute on chronic kidney disease highest with 8.5 . 55\% would strongly advocate for escalation (score 8,9 or 10). Of the 21 who did not favour escalation to ICU (score 1-5), "unlikely to survive ICU admission" (80\%) and "end stage organ disease" (85\%) were the most frequently cited reasons, and 6 cited "lifestyle decision". 9 recommended making the patient DNACPR and 3 would institute palliative care measures. Of the majority who would consider escalation, 69\% recommended "No limits on care - full escalation". In a separate question $34 \%$ of all respondents said they "frequently" (12\%) or "sometimes" (21\%) considered resource utilisation or cost when making individual clinical decisions on escalation of care.

Conclusion Most respondents favoured escalation of care to some degree, however a significant minority interpreted the same clinical information with a degree of prognostic pessimism. Continued education regarding early opportunities to improve prognosis in decompensated liver disease is required.

Disclosure of Interest None Declared.
PTU-129 THE ROLE OF PRIMARY RESECTION AND HEPATIC RESECTION IN THE MANAGEMENT OF METASTATIC PANCREATIC NEUROENDOCRINE TUMOURS WITH IRRESECTABLE LIVER METASTASES

${ }^{1} \mathrm{~L}$ Mills, ${ }^{2} \mathrm{R}$ Srirajaskanthan*, ${ }^{3} \mathrm{~J}$ Ramage, ${ }^{4} \mathrm{~A}$ Prachalias, ${ }^{4} \mathrm{P}$ Srinivasan, ${ }^{4} \mathrm{~K}$ Menon, ${ }^{5} \mathrm{~A}$ Quaglia, ${ }^{4} \mathrm{~N}$ Heaton. ${ }^{1}$ ENETS Centre of Excellence, Institute of Liver Studies, King's College Hospital, UK; ${ }^{2}$ Department of Gastroenterology, University Hospital Lewisham, London, UK; ${ }^{3}$ Department of Gastroenterology, Hampshire Hospitals NHS Trust, Basingstoke; ${ }^{4}$ Hepatopancreatobiliary Surgery, Institute of Liver Studies, King's College Hospital, London, UK; ${ }^{5}$ Department of Histopathology, Institute of Liver Studies, King's College Hospital, London, UK

\subsection{6/gutjnl-2014-307263.203}

Introduction More than $40 \%$ of pancreatic neuroendocrine tumour (PNET) patients have liver metastases (LM) at diagnosis. Whilst it is agreed that, where possible, curative surgery offers the best outcomes, the role of debulking surgery in the context of irresectable LM remains unclear. There is also no clear evidence to support resection of the pancreatic primary in the context of irresectable liver metastases. The aim of this study is to investigate the survival benefits of different surgical treatments of LM.

Methods The notes of 111 PNET patients who had visited King's since 2004 were reviewed. 53 had LM at diagnosis and were divided into 3 cohorts: No Resection (NR) n $=27$, Pancreatic Resection (PR) $\mathrm{n}=6$ and Pancreatic and Liver Resection (PLR) $\mathrm{n}=11$. Median follow-up was 40.2 months.

Results Median survival for all patients with liver metastases was 61.1 months. Survival was significantly worse for patients with no resection; NR (23 months) vs. PR (98 months) $\mathrm{p}=0.047, \mathrm{NR}$ (23 months) vs. $\operatorname{PLR}(\mathrm{n} / \mathrm{a}) \mathrm{p}=$ 0.008 , but there was no significant difference between PR and PLR. Of the 11 PLR patients, 6 received debulking rather than curative resection. Univariate analysis showed no significant survival difference between dubulking and curative liver resection; however, multivariate analysis showed that resectability of liver metastases was not a significant prognostic variable.

Conclusion Resection of the primary significantly improves survival in the presence of irrespectable liver metastases.

There may be a role for debulking surgery in patients with irresectable liver metastases, however, the data so far does not appear to suggest a survival benefit over primary resection alone; larger studies are needed.

Disclosure of Interest None Declared.
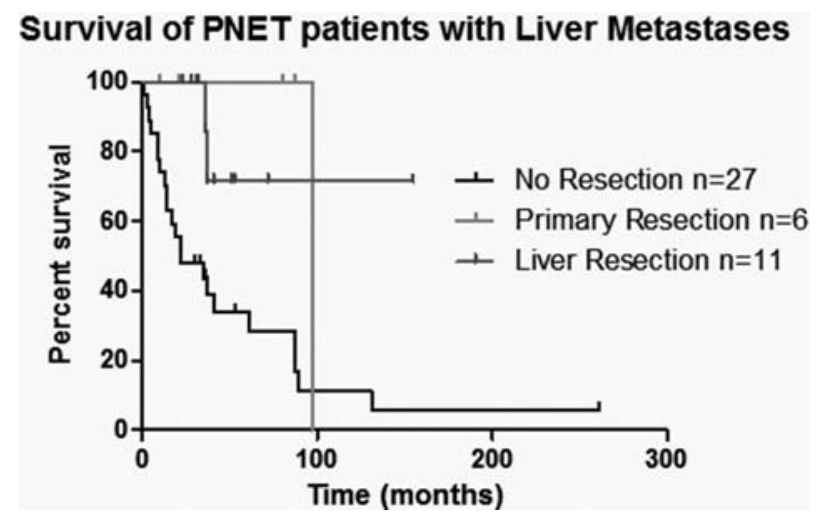

Abstract PTU-129 Figure 1 